\title{
The Role of Cross-Domain Use Cases in IoT - A Case Analysis
}

\author{
Sebastian Bär \\ Leipzig University \\ sbaer@,wifa.uni-leipzig.de
}

\author{
Olaf Reinhold \\ Leipzig University \\ reinhold@wifa.uni-leipzig.de
}

\author{
Rainer Alt \\ Leipzig University \\ alt@wifa.uni-leipzig.de
}

\begin{abstract}
The strong rise of Internet connected things contributes to the big data phenomenon. Data is increasingly becoming available from various devices in large volume, variety and velocity. However, many Internet of Things (IoT) applications still seem to be used to solve single problems and infrastructural elements (e.g. sensors or data) are not openly available for other use cases. This paper argues that a growing need for crossdomain applications is approaching within the sharing economy and other ecosystem-based business models. It investigates the current state of such cross-domain applications by analyzing currently deployed IoT case studies. The analysis shows that most cases remain in the silo mentality and focus on a specific domain. Only a few cases feature some cross-domain characteristics. These are especially present in smart city cases, which engage multiple stakeholders and promote the share of resources.
\end{abstract}

\section{Introduction}

Currently, almost every new device is smart, thus providing a basis for gathering data that was barely accessible before. According to a recent study of Gartner [1] there will be 20 billion internet connected devices in 2020 , implying a never before existing pool of potential data sources. This so called Internet of Things (IoT) is defined as the interconnection of sensing and actuating devices that are connected through a unified network and share data that enables the development of innovative applications [2].

IoT enabled scenarios can be found in many different application areas, such as home and building, city, factory, healthcare, environment, transportation or agriculture. The typical pipeline of such use cases includes generating and gathering sensor data. This data is routed via a gateway to a central storage and management interface, where it is preprocessed and analyzed with expert knowledge for achieving the analysis goal. However, in most cases, the purpose of such a pipeline is to solve one specific problem or demand. The obtained information is kept as an asset to achieve competitive advantage [3].
New disruptive approaches open those silos and enable the creation of additional business values through cooperation. The concept of platform business models motivates a rethinking of the original one-directional relationship between producers and consumers to twosided or multi-sided markets (e.g. Airbnb), where consumers and producers generate value for each other ([4], [5], [6], [17]). Once a resource, such as a sensor, has been deployed, it can be shared for generating additional values in other application areas (i.e. domains). With the increasing availability of sensors, sensor data, analytical services and expert knowledge in many different application areas, new scenarios, that build upon assets across these application areas, become possible ([7], [8]).

One example for the diffusion of sensors and various cross-domain applications is the ecosystem of the Apple Watch. The watch comprises positioning, altimeter, heart rate, accelerometer, gyroscope and ambient light sensors in a small size [9]. Besides hardware, Apple has also established an ecosystem where developers can build applications to create additional services for users based on their devices. Apple offers sensors in terms of devices, defines interfaces for application developers to access those sensors and has launched a marketplace, where developers may offer their services to users of Apple devices. The available application fields based on the same set of sensors are numerous and diverse, e.g. health, fitness, nutrition or travel. In some cases, Apple itself offers applications, for example Health. In May 2018 about 100k applications existed in the Apple App Store in the category health and fitness [10].

This paper investigates the cross-domain aspect in IoT cases and discusses potential building blocks that could support use cases beyond single domains. The research questions of this paper are: (RQ1) How do crossdomain scenarios differ from single-domain scenarios? (RQ2) Which characteristics of those solutions enable or support cross-domain applications?

For answering these questions, a definition of crossdomain is developed and applied for an explorative analysis of available IoT case studies regarding the representation of cross-domain features, the role of key enablers and basic architectural components. The remainder of this paper is structured as follow. First, the concept of cross-domain is introduced. Second, relevant 
terms and existing research is described. Third, an explorative web and literature review is prepared and conducted. Fourth, cases are evaluated. Each case study is classified to high, low or not-cross-domain. Fifth, the case studies are discussed in terms of architecture, functionalities and IoT use cases. The case studies are analyzed based on challenges that cross-domain IoT applications need to address. Finally, the findings are summarized and directions for future research are suggested.

\section{Cross-domain IoT use cases}

The term domain has manifold meanings, e.g. a field of interest, the range of personal knowledge, land ownership or a region characterized by a specific feature [11]. In the case of IoT, the term domain may be differentiated into three concepts: knowledge, institutional and data perspective. The first refers to the area of knowledge or skill that a participant yields, for example in health, biology or economics. The second specifies the origin of the involved parties. That might be an industry sector or if the used resources are internal or external. The last describes the generated or used data: types of used data, classifications, data ownership, data format or units of measurement. The focus in this paper is on the institutional perspective.

A typical single-domain IoT solution consists of the following building blocks [12] (see Figure 1). Sensors gather environmental data, such as temperature, location or movements. The gateway or middleware unifies different sensors in terms of protocols (e.g. Wi-Fi), can filter data or forward sensor data to several destinations. In simple cases, the gateway might be omitted. The gateway sends the data to a platform where data is collected and stored. Once the data has been merged, further resources might be integrated and data aggregation as well analysis can be done. Finally, the information is presented or served in visualization or applications.

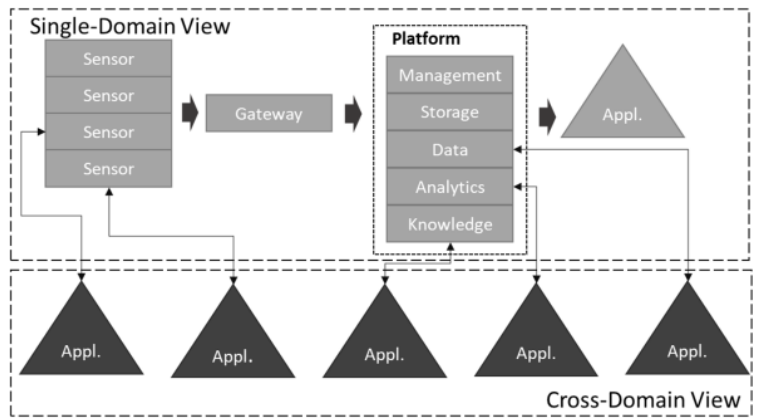

Figure 1: Building blocks of IoT solutions (based on [12])

As shown in the lower part of Figure 1, those building blocks could be reused beyond the original applica- tion and domain. Different approaches describe technical or strategic steps to enable the collaboration of IoT solutions vertically ([7], [13]). Gyrard et al. [13] focus on technical issues in cross-domain applications. A framework is introduced to build IoT applications, to support users in interpreting sensor data and to combine data of different domains. Miorandi et al. [7] examined the present IoT landscape in terms of technologies, applications and future challenges. They observed that the current solutions are single application domain or single technology centric and need to be more open in networking and building communities.

There are approaches for connecting communities on a non-technical level, such as SixTwentyTen [24]. Their focus is to link interest groups from the same as well as from other domains. Another example for the cooperation beyond domains could be the Code for All [25] initiatives. The initiatives consist of participants from different technical and topical knowledge that form a loose working group to deal with a specific interest based on datasets of Open Data. On Kaggle [26] companies may upload a dataset and describe a specific problem and contributors from various origins, skills and subjects compete to deliver the best solution for that data.

\begin{tabular}{|c|c|c|}
\hline Enabler & Keywords & Examples \\
\hline Semantic Web & $\begin{array}{l}\text { Semantic Web, Linked } \\
\text { Data, RDF, OWL, Data } \\
\text { Standardization }\end{array}$ & {$[14],[15],[16]$} \\
\hline $\begin{array}{l}\text { Ecosystem } \\
\text { Management }\end{array}$ & $\begin{array}{l}\text { Ecosystem, Platform, } \\
\text { Platform Ecosystem, } \\
\text { Community }\end{array}$ & $\begin{array}{l}{[17],[18],[4],} \\
{[6],[19]}\end{array}$ \\
\hline $\begin{array}{l}\text { Big Data Archi- } \\
\text { tectures }\end{array}$ & Architecture & {$[20],[21]$} \\
\hline IoT & $\begin{array}{l}\text { Applications, Architec- } \\
\text { ture, M2M }\end{array}$ & $\begin{array}{l}{[7],[22],[13],} \\
{[2],[12],[23]}\end{array}$ \\
\hline
\end{tabular}

Table 1: Challenges for cross-domain IoT solutions

From existing research, several approaches may be observed that seem important for the development of cross-domain applications (see Table 1). New techniques and frameworks of Semantic Web may ease the handling of versatile data in the same use case as well as in cases beyond the border of a single use case. Methods and platforms for ecosystem management create visibility and connect stakeholders that could cooperate for mutual benefits. The better availability of big data architectures provide the means for storing and processing the vast amount of incurring data. Technical progress in IoT-technology adds the ability to connect even more devices, process data in sensors directly or in direct communication between sensors. 


\section{Research methodology}

To gain insights in current activities and developments in IoT solutions that involve multiple domains an explorative web and literature reviews for case studies in IoT was performed. Following Brocke et al. [27] five steps for a structured literature review are defined: review scope, conceptualization of the topic, literature search, literature analysis and synthesis and the derivation of a research agenda. Benbasat et al. [28] state that "(...) case research strategy is well-suited to capturing the knowledge of practitioners and developing theories from it." To contrast different approaches in IoT a multiple case study review is carried out [29].

The review scope may be described following the taxonomy of Cooper [30]. The focus of the survey is on applications. Those applications should reveal central issues on already deployed IoT solutions. A neutral position is taken, the coverage is pivotal. The review is conducted in a conceptual manner. General scholars and practitioners are the targeted audience.

\begin{tabular}{|c|c|}
\hline Variables & Definition \\
\hline $\begin{array}{l}\text { Internet } \\
\text { of Things }\end{array}$ & $\begin{array}{l}\text { "In the IoT, "things" are expected to become } \\
\text { active participants in business, information } \\
\text { and social processes where they are enabled } \\
\text { to interact and communicate among them- } \\
\text { selves and with the environment by exchang- } \\
\text { ing data and information "sensed" about the } \\
\text { environment, while reacting autonomously to } \\
\text { the "real/physical world" events and influ- } \\
\text { encing it by running processes that trigger ac- } \\
\text { tions and create services with or without di- } \\
\text { rect human intervention." [31] }\end{array}$ \\
\hline $\begin{array}{l}\text { Case } \\
\text { Study }\end{array}$ & $\begin{array}{l}\text { "A case study examines a phenomenon in its } \\
\text { natural setting, employing multiple methods } \\
\text { of data collection to gather information from } \\
\text { one or a few entities (people, groups, or or- } \\
\text { ganizations). The boundaries of the phenom- } \\
\text { enon are not clearly evident at the outset of } \\
\text { the research and no experimental control or } \\
\text { manipulation is used." [28] }\end{array}$ \\
\hline $\begin{array}{l}\text { Cross- } \\
\text { Domain }\end{array}$ & $\begin{array}{l}\text { The term domain may be differentiated into } \\
\text { three concepts: knowledge, institutional and } \\
\text { data perspective, [... ( (see section } 2 \text { ) }\end{array}$ \\
\hline
\end{tabular}

Table 2: Definition of key concepts for literature and web search

Table 2 shows the variables that were used for conducting a literature and web search. At first, a web research was carried out. Due to the large amount of hits for the web search, only the first 150 results were analyzed for relevant cases by reading titles and abstracts. The material needed to be directly accessible, e.g. on web pages or in whitepapers. To add an academic perspective, a literature review on EBSCOhost followed. No specific journals or conferences were selected as many journals or conferences might deal with the topic. To ensure sufficient quality, only peer-reviewed journals and conferences were regarded. Titles and abstracts were scanned to retrieve relevant articles. Afterwards the identified cases were filtered again to ensure that the description of the case itself is sufficient. For each result, both web and literature, the surroundings were examined for further cases by forward and backward search.

The search was realized by the use of the following search terms:

(1) "Internet of Things" AND ("Case Study" OR "Case Studies") AND ("cross-domain" OR "interorganizational")

(2) "Internet of Things" AND ("Case Study" OR "Case Studies")

(3) "Internet of Things" AND ("Use Cases" OR "Use Cases")

To gain first insights to the current state-of-the-art in IoT applications, only implemented and published case studies were regarded. Therefore, the case study should present a solution that has already been deployed to express the current situation. The description had to contain why that solution was needed and what criteria had led to the chosen approach. The underlying technical infrastructure should be described sufficiently.

\begin{tabular}{|c|c|c|c|c|c|}
\hline $\begin{array}{l}\text { Data- } \\
\text { base }\end{array}$ & $\begin{array}{l}\text { Search } \\
\text { Terms }\end{array}$ & $\begin{array}{l}\text { Re- } \\
\text { sults }\end{array}$ & Hits & $\begin{array}{l}\text { Forw/Back } \\
\text { w. Search }\end{array}$ & $\begin{array}{l}\text { Net. } \\
\text { Hits }\end{array}$ \\
\hline \multirow[t]{3}{*}{ Web } & $(1)$ & $47 \mathrm{k}$ & 0 & 0 & 0 \\
\hline & (2) & $\begin{array}{c}29.8 \\
\mathrm{~m}\end{array}$ & $\begin{array}{c}105 \\
(11)\end{array}$ & $23(1)$ & 12 \\
\hline & (3) & $4.7 \mathrm{~m}$ & 0 & 0 & 0 \\
\hline \multirow{3}{*}{$\begin{array}{c}\text { EB- } \\
\text { SCO }\end{array}$} & (1) & 0 & 0 & 0 & 0 \\
\hline & (2) & 324 & $5(1)$ & 0 & 1 \\
\hline & (3) & 137 & 0 & 0 & 0 \\
\hline
\end{tabular}

Table 3: Result of literature and web search

The individual case studies had to contain the purpose of the solution, e.g. monitoring, reporting or prediction. The resulting documents were scanned for those criteria. To answer questions like "if a network of partners exists" further publications on web pages, whitepapers or videos of involved partners were regarded. If all criteria matched, the case study was included, otherwise it was omitted. For example, Cisco [34] was labeled as IoT case study, but actually dealt with extending radio networking capabilities in harsh regions of Alaska. The main focus was on the network, not on the internet connectivity of the used devices. Another example is $I B M$ [35] where challenges and benefits of integrating several processes into one holistic approach are discussed without technical aspects or specific use cases. 
For evaluating the criteria from Table 1, the coverage of the mentioned topics in the case studies was analyzed. For example in Libelium [36], the need for handling big data is mentioned, so an appropriate platform architecture was chosen. The same approach was applied for the other challenges as well.

\begin{tabular}{ll}
\hline \multicolumn{1}{c}{ Category } & \multicolumn{1}{c}{ Criteria } \\
\hline IoT Scenario [7], [2] & Use Case \\
\hline \multirow{2}{*}{ Cross-domain (own) } & $\begin{array}{l}\text { Involved Sectors } \\
\text { Use of External Resources }\end{array}$ \\
\cline { 2 - 2 } & $\begin{array}{l}\text { Sharing of Resources } \\
\text { Use Case-specific }\end{array}$ \\
\hline Platform Characteristics [32] & \begin{tabular}{l} 
Network of Partners \\
\cline { 2 - 2 } Involved Partners
\end{tabular} \\
\hline Benefitting Users \\
\hline Community Aspects [19] & $\begin{array}{l}\text { Openness, Sociality, Con- } \\
\text { tribution }\end{array}$ \\
\hline Business Analytics [33] & Type of Analysis \\
\hline
\end{tabular}

Table 4: Criteria for evaluating the case studies

Each case study was categorized in an IoT category, based on Miorandi et al. [7] and Gubbi et al. [2]. To evaluate the cross-domain degree of a case study, the above-described criteria were applied (see Table 4). For assessing the relationship between the different involved or potential partners of each case study, criteria from Schreieck et al. [32] were used. The community aspects for integrating users with each other and thrive external contributions were adopted from Schlagwein et al. [19]. To enable the comparison of the analytics in each case the taxonomy of Delen and Demirkan [33] was utilized.

From an institutional perspective, the number of involved partners and their source domain was regarded. The origin of a partner was classified by the Statistical Classification of Economic Activities in the EU [37]. This classification provides categories which help to asses a partner's activity in order to identify cooperation beyond the own domain. The number of involved partners is counted by the quantity of partners contributing to the solution or benefitting from it. Another opportunity to dissolve a need for information is the use of external resources that might come from different organizations or areas of knowledge. Furthermore, if a company shares its own resources, that need for information could be fulfilled in additional use cases. To enable the contribution of external partners, the technical infrastructure must be open and publicly accessible. It is evaluated if the solution is open to external users, if they already contribute or how community aspects support the involvement of new contributors. It is examined how partners support each other in building the solution. Existing networks of already integrated partners might ease the building of further solutions. The use of the gathered data was classified in descriptive, predictive and prescriptive business analytics. Furthermore, it was noted if the solution is domain-specific or general purpose. A domain-specific solution is fitted to address a single use case, e.g. vineyard, where sensors, analysis or architecture cannot or hardly be used in other use cases. The use of a public cloud infrastructure offers potentially more interfaces than private cloud or in-house solutions [38].

\section{Literature analysis and synthesis}

In the following, the outcomes of the search and the reviewed case studies are presented. The results for the different search queries are illustrated in Table 3. The majority of case studies resulted from the web review as the academic literature mainly yielded publications that implemented proposals from scientific research for validation. Implementations of IoT scenarios claiming themselves as cross-domain or interorganizational were not found. The term use case did not lead to the desired results because the term was obviously more used for possible areas of applications instead of specific implementations. For example, Verba et al. [39] propose and validate a new framework, but only in a scientific environment. As a result of the web and literature search, 13 case studies (see Table 5) were included.

\begin{tabular}{|c|c|c|}
\hline Name & $\begin{array}{l}\text { IoT- } \\
\text { Cate- } \\
\text { gory }\end{array}$ & Short Description \\
\hline $\begin{array}{l}\text { City of Til- } \\
\text { burg Moni- } \\
\text { toring [40] }\end{array}$ & $\begin{array}{l}\text { Smart } \\
\text { City }\end{array}$ & $\begin{array}{l}\text { Automated monitoring of wa- } \\
\text { ter/air quality, noise, people } \\
\text { movement with public website }\end{array}$ \\
\hline $\begin{array}{l}\text { Smart Park- } \\
\text { ing [41] }\end{array}$ & $\begin{array}{l}\text { Smart } \\
\text { Trans- } \\
\text { porta- } \\
\text { tion }\end{array}$ & $\begin{array}{l}\text { Sensor-based public car park } \\
\text { information for better travel } \\
\text { schedule and planning, data } \\
\text { freely available }\end{array}$ \\
\hline $\begin{array}{l}\text { Smart Cities } \\
\text { Santander } \\
{[42]}\end{array}$ & $\begin{array}{l}\text { Smart } \\
\text { City }\end{array}$ & $\begin{array}{l}\text { Sensors for many different use } \\
\text { cases (e.g. environment, traffic, } \\
\text { lights, garbage, security) }\end{array}$ \\
\hline $\begin{array}{l}\text { Heidelberg } \\
\text { Connected } \\
\text { Printing } \\
\text { Press [43] } \\
\end{array}$ & $\begin{array}{l}\text { Smart } \\
\text { Busi- } \\
\text { ness }\end{array}$ & $\begin{array}{l}\text { Remote sensors in printing ma- } \\
\text { chines for automated er- } \\
\text { rors/alerts, predictive mainte- } \\
\text { nance and peer benchmarking }\end{array}$ \\
\hline $\begin{array}{l}\text { AGCO Con- } \\
\text { nected Farm } \\
{[44]}\end{array}$ & $\begin{array}{l}\text { Smart } \\
\text { Agri- } \\
\text { culture }\end{array}$ & $\begin{array}{l}\text { Analysis of benefits or prob- } \\
\text { lems of AGCO IoT-solution for } \\
\text { precision agriculture }\end{array}$ \\
\hline $\begin{array}{l}\mathrm{CNH} \text { Indus- } \\
\text { trial Vehicles } \\
{[45]}\end{array}$ & $\begin{array}{l}\text { Smart } \\
\text { Trans- } \\
\text { porta- } \\
\text { tion }\end{array}$ & $\begin{array}{l}\text { Precise monitoring of vehicles, } \\
\text { in transportation and agricul- } \\
\text { ture through connected devices } \\
\text { and supply chain }\end{array}$ \\
\hline $\begin{array}{l}\text { Rolls Royce } \\
\text { Aircraft En- } \\
\text { gines [46] }\end{array}$ & $\begin{array}{l}\text { Smart } \\
\text { Busi- } \\
\text { ness }\end{array}$ & $\begin{array}{l}\text { Machine sensors to gather, ag- } \\
\text { gregate, analyze data for fault } \\
\text { detection and high availability }\end{array}$ \\
\hline $\begin{array}{l}\text { Omica Preci- } \\
\text { sion Farming } \\
{[47]}\end{array}$ & $\begin{array}{l}\text { Smart } \\
\text { Agri- } \\
\text { culture }\end{array}$ & $\begin{array}{l}\text { Monitoring of crop, water and } \\
\text { fertilizer requirements with } \\
\text { smart sensors, decision support }\end{array}$ \\
\hline
\end{tabular}




\begin{tabular}{lll}
\hline $\begin{array}{l}\text { Carestream } \\
\text { Healthcare } \\
{[48]}\end{array}$ & $\begin{array}{l}\text { Smart } \\
\text { Busi- } \\
\text { ness }\end{array}$ & $\begin{array}{l}\text { Monitor system health and us- } \\
\text { age data to enable quick replen- } \\
\text { ishment through cloud con- } \\
\text { nected machines }\end{array}$ \\
\hline $\begin{array}{l}\text { Veolia Water } \\
\text { Quality } \\
\text { Monitor [49] }\end{array}$ & $\begin{array}{l}\text { Smart } \\
\text { Meter- } \\
\text { ing }\end{array}$ & $\begin{array}{l}\text { Widely distributed sensor- } \\
\text { based measuring of water qual- } \\
\text { ity and pressure, detect er- } \\
\text { rors/leakages }\end{array}$ \\
\hline $\begin{array}{l}\text { ELM Energy } \\
\text { [50] }\end{array}$ & $\begin{array}{l}\text { Smart } \\
\text { Grid }\end{array}$ & $\begin{array}{l}\text { Real-time monitoring of dis- } \\
\text { tributed energy systems }\end{array}$ \\
\hline $\begin{array}{l}\text { iWesla Wa- } \\
\text { ter Manage- } \\
\text { ment [36] }\end{array}$ & $\begin{array}{l}\text { Smart } \\
\text { ing }\end{array}$ & $\begin{array}{l}\text { Improving water efficiency and } \\
\text { safety in living areas by moni- } \\
\text { toring demand, send orders }\end{array}$ \\
\hline $\begin{array}{l}\text { Headfirst } \\
\text { Health [51] }\end{array}$ & $\begin{array}{l}\text { Smart } \\
\text { Health }\end{array}$ & $\begin{array}{l}\text { Monitoring patients remotely } \\
\text { in their homes, emergency alert }\end{array}$ \\
\hline
\end{tabular}

Table 5: Analyzed case studies

To address the diverse understanding of what a domain is, each surveyed case study was categorized by the degree of its cross-domain characteristic (high, low, not cross-domain). A case was categorized as high cross-domain when it fulfilled at least two criteria, for example, it incorporates three different sectors and certain resources are shared. A low assignment applied for one matching criterion. Cases, where no dimension was beyond the own domain, were categorized as not crossdomain (see Table 6). Regarding RQ1, there were three case studies with a high cross-domain characteristic, six with a low and four that were not regarded as cross-domain. The high cross-domain applications utilized several domains and shared their resources, more precisely their data. The low group either incorporated external resources or shared their own, again with a focus on data.

\section{Discussion}

\subsection{Cross-domain nature in IoT scenarios}

Following, the conceptualization of cross-domain as presented in section 2, most of the evaluated case studies were either low or not cross-domain. It could be observed that cases categorized as high, involved multiple sectors and shared their resources for external use. Remarkably, every high cross-domain case was based on a smart city scenario. The low-categorized cases used external resources or shared their resources with externals, but only one sector was involved. In every case where resources, primarily data, were shared, the use of the data had already been specified in advance. The architectures are in line with the model of Lee and Lee [12] as described in Figure 1. In terms of platform characteristics, in half of the cases data was stored in a public cloud and in the other in a private cloud. In most cases, large vendors of software platforms were used. In cases where the platform was only described as "own", still those vendors might be used in a white label approach.
Usually, data collection, preprocessing, analysis and visualization are done in one single place. In some cases, the analysis or some part of it involved an additional infrastructure. In one case, data storage and the general analysis occurred in a central component, machine learning aspects took place in an additional cloud component and results were returned. The visualization was available in a third cloud component based on the central platform. The number of involved partners that build a solution ranged from one to more than three different partners.

Regarding business analytics, less than half of the reviewed applications aimed to predict future states based on the gathered data, e.g. they predict machine failure to schedule earlier maintenance and avoid outages. Prescriptive analytics examines how different decisions might affect future states. However, in none of the surveyed cases a prescriptive analysis was present.

Various types of typical IoT use cases were observed. The discussed not-cross-domain use cases originated from smart metering/grid and health care. In health care, privacy issues might be the limiting factor.

Regarding the Smart City environment, community aspects were addressed only partially since, obviously, the lead was taken by public administration. In general, an apparent problem of the administration is solved but additionally, for example, the incurring data are shared to enable further usage. Reasons for that are: to inform citizens and increase transparency, due to legal requirements or to enable external innovation by companies (to enhance their own services) or even citizens (e.g. Open Data). As a city unites several stakeholders in different areas (e.g. traffic management, parking management, urban transportation, social services, environment, park and garden management, public security, etc.), multiple/different domains are available for integration. The low cross-domain case studies integrated external data or shared their own. In addition, external data was integrated. For example, satellite data was used to track the position of goods or to be combined with sensor data in precision agriculture. Weather data may be used to plan irrigation or to predict yields as well as be an influencing factor in operating machines. In the industrial context customers share their (e.g. machine) data with the vendor to enable better monitoring and maintenance. Vendors can improve services by comparing metrics of all their distributed units. In other cases, the data was shared with suppliers to enable, for example, automated replenishment or supply.

\subsection{Enablers of cross-domain scenarios}

In the following, the occurrence and role of the identified enablers from section 2 is reviewed as those may enable or thrive cross-domain scenarios. 
To simplify the interoperability of IoT solution technologies, the semantic web concept could be used. The application of ontologies and supporting standardized technologies, such as Resource Description Framework or Web Ontology Language would describe available data to support the understanding and use of it in further cases. When data is shared, the use of standardized and machine-readable formats and interfaces yields further use cases. However, none of the regarded case studies mentioned the use of semantic techniques. Neither the use of semantic web for building a solution nor the characteristics of shared or externally used data were specified. Despite many research projects that engaged in the combination of semantic web and IoT solutions (see [52-54]), an adoption in practice was not found in the present search. Further, the used formats and interfaces for data sharing or the consumption of external data were scarcely documented.

Ecosystems may also enable cross-domain scenarios, since they stimulate cross-side network effects between participants, where each participant benefits from the additional exchange [4]. Many vendors offer networks of partners for specific tasks (e.g. [40], [42], [42]). In several cases, there is one central vendor where activities were found (e.g. Libelium in [36] or [40]). The partner network is often used (e.g. [36], [40], [46], [51]) and the collaboration with recurring partners might decrease transaction costs and enable tighter integration. Beyond that, the ecosystems were not widely open. Openness, sociality and contribution to foster additional exchanges were not predominant. However, an exchange between vendors and several customers was found ([43], [48]). For example, customers shared machine data with the machine vendor. Through comprehensive data, the vendor can offer improved services for all customers like predictive maintenance. External innovation is not possible as the machine vendor either bars external providers or the offered services of a partner or a network of partners were not profoundly described. Therefore, customization to enable specific applications might be required. With an ecosystem, where offered services, for example sensors, sensor management, data storage capabilities and analytical techniques were well-defined, a step towards simply picking and combining building blocks could be made, enabling customers to build a basic solution in self-service.

The term big data is often characterized through the five Vs: volume, variety, velocity, value, veracity. Big data comprises a large amount of heterogenic, cross-domain data, generated in short time from various sources that come into value. To address all different Vs, novel data models, analysis techniques, tools and infrastructure are needed. On the one hand, large platform vendors provide big data capabilities implicitly. On the other hand, several cases mention their necessity to be able to process large amounts of data ([36], [43], [44], [51]). However, neither the needs nor the actual provisions for architecture or organization are described in detail.

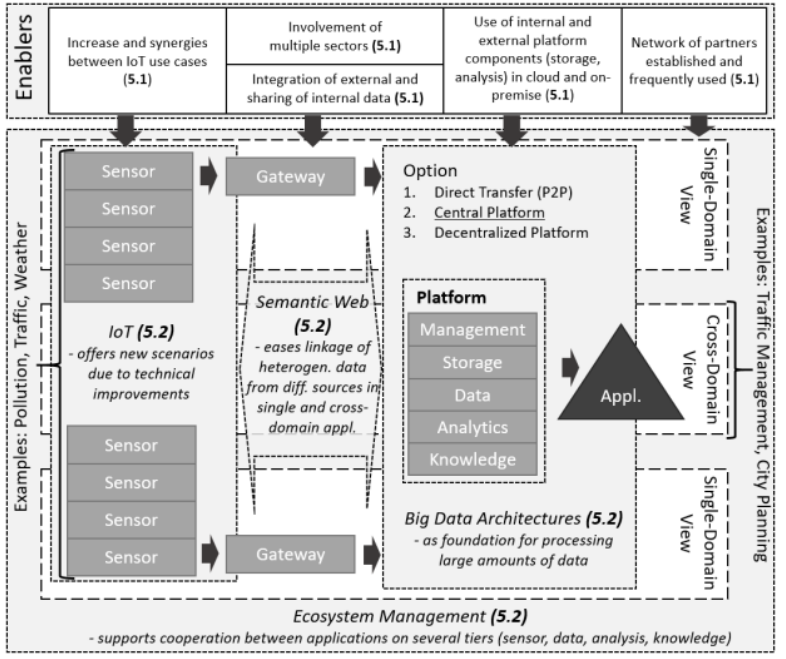

Figure 2: Design elements and enablers for cross-domain applications

The use of $I o T$ is wide and growing. Various applications are available as sensors, gateways and big data capabilities in storage and analysis are available. The next steps in IoT are: Edge computing, including additional data, Web of Things, from rule-based monitoring to predictive. Edge computing is the computation and analysis done on the edge of the sensor network instead of the cloud platform. This saves bandwidth, filters noise out of the data, time-critical analysis and decisions can be done instantly. The interoperability of sensors or IoT solutions could be improved by semantic web techniques, but no case showed or indicated the use of semantic technologies. The application of standards is not described (e.g. W3C's Semantic Sensor Network). The use of external data is found rarely, how these data were chosen and how they are connected with internal data ([44], [46], [47]) is not specified. The sharing of data took place in multiple use cases. Data was shared between customer and vendor, to improve the vendors' services, between customer and suppliers, to allow quicker replenishments on demand and to citizens or respectively, the public. Based on this section, RQ2 may be answered. The results of the survey show that there is no systematic approach to support cross-domain applications. The examined use cases fail to describe a common pipeline for building applications that support cross-domain characteristics. In general, no concrete information is given about the handling of data or knowledge of multiple domains, e.g. with semantic description. A combination of IoT building blocks and the impact of the discussed challenges can be seen in Figure 
2. The challenges show how parts of different application could be combined to create a new application.

\subsection{Implications for practice and research}

In contrast, Apple addresses technical and organizational requirements to enable external contribution. Apple produces sensors in the form of consumer hardware. The hardware is open for interoperability through defined interfaces, which enables external innovation from third-party developers. Those developers and consumers are connected through a marketplace, where developers can monetize their efforts. The marketplace offers categories and user rating, outstanding applications are regularly promoted and every application has to be approved by Apple before its release. Various approaches illustrate the ability of platforms to create value by connecting different actors that would otherwise not be connected [55]. The new opportunities increase with the number of actors on the opposite side. In the examined case studies, those actors are divided by domains, where the connections between the domains are unutilized. The high cross-domain cases connect those separate actors, that could otherwise not offer specific services or only with higher efforts. To make use of those currently unused potentials, an attempt to overcome those borders can be made. A first step to connect those actors could be to share resources on a centralized platform. Each participant could decide individually which part of their own solution is shared for which incentive. The central instance might define interfaces, prices, offer matchmaking, infrastructure etc. that enable combining resources from different donors. The IoT solution itself can live independently from the central sharing platform as the contribution is voluntary. Next to centralized platforms, decentralized approaches are emerging. Decentralized technologies, such as blockchain, broaden their usability from the initial purpose as cryptocurrency to multiple use cases as a distributed ledger in IoT [56]. In times of billions of smart devices, data could be shared in real-time, but restrictions in bandwidth, traffic, analysis capacities or central points of failure arise. A blockchain, as a decentral platform, may reduce the pivotal administration of a platform operator and promote new solutions.

Researchers should address the transfer of the discussed challenges to practical applications. Cross-domain applications should be implemented to demonstrate the potential for practitioners and the current frameworks (e.g. [13] or [52]) should be reviewed to find reasons for the lack of adoption. Guidelines for designing cross-domain application could be developed to answer for instance the following questions: What are problems that cannot be solved in a single domain, but would benefit from the input of another domain? How could a supporting domain be identified and what stimulates the mutual cooperation?

\section{Conclusion}

The goal of this paper was to analyze currently deployed IoT solutions to identify approaches that exceed a single application domain. A definition of a cross-domain concept with criteria to classify single and crossdomain case studies was developed. The examination of several case studies revealed that especially smart cities feature cross-domain applications ([40], [41], [42]). Obviously, smart city use cases are prevalent cross-domain solutions because many different stakeholders are involved with their interests. In general, such projects are driven by city administrations to provide services for citizens or companies. As those services are fundamental and inalienable, the focus is on improving efficiency instead of commercial use. Additionally, data is shared to increase transparency or motivate participation by companies or citizens. Consequently, the attempt to achieve a competitive advantage is not as predominant as in, e.g., industrial projects. In the other cases only little cooperation was observed, which may be due to lacking benefit. In two cases ([43], [48]), the machine vendors supported the sharing of data across customers. Here, the benefits are well defined: the vendors can improve their services due to a holistic view on their operating machines; customers can only benefit from those achievements, when they share their own data respectively.

Only the minority of the surveyed case studies is categorized as high cross-domain. The majority is either low or not cross-domain. The underlying technical infrastructure is, in most cases, currently not focused on supporting cross-domain applications. The reason for this is not evident. If there is no need or incident for cross-domain functionalities, no effort will be made. If an exchange of resources exists, exclusively data is regarded. The sharing of further resources, e.g. models for irrigation or traffic forecasting, could not be identified. The mentioned challenges from Table 1, that facilitate interorganizational cooperation, are rarely discussed.

The Apple example illustrates the potential for sophisticated ecosystem management [57] in IoT applications to overcome the silo mentality and use the potential of business value through cooperation. To achieve such an approach several requirements for a cross-domain IoT scenarios can be derived (see Figure 2). In general, a platform needs to be open for external contributors. Interfaces from and to the platform should be defined. To support building solutions, visibility between participants must be created. The available resources should be described semantically to support an 
easier understanding when manifold domains are involved. As a consequence, to the growing amount of IoT devices and therefore data, the volume of such a platform needs to be capable of storing and processing a huge quantity of data. As parts of an ecosystem, incentives for getting involved are necessary. To increase the use, additional layers might be added. A domain expert can help potential users in integrating data in their specific use case. Analytical services or technologies could be shared as well. Parts of the described approach already exist, as for example data marketplaces [58]. Data marketplaces symbolize only one view of a cross-domain use case - the data perspective. However, a holistic view might increase the benefits even further.

The conducted research has limitations that should be addressed in future research. The aim of this research was a first analysis of the concept and constructs of the cross-domain aspect based on the analysis of IoT cases. As case studies describe a particular external view, not all internal regarded topics could be analyzed. To reveal further information, more in-depth interviews should be conducted. The used search terms for the literature and web review were quite narrow. In another iteration, more general terms, e.g. scenario, case or solution, could be added to obtain more results.

The authors received financial support of this research by the Development Bank of Saxony (SAB) and the European Social Fund (ESF) within the project $S 2 D E S$.

\section{References}

[1] https://www.gartner.com/newsroom/id/3598917, accessed 12-6-2017.

[2] Gubbi, J., R. Buyya, S. Marusic, and M. Palaniswami, "Internet of Things (IoT): A vision, architec-tural elements, and future directions", Future Generation Computer Systems, 29(7), 2013, pp. 16451660 .

[3] Soursos, S., I.P. Zarko, P. Zwickl, I. Gojmerac, G. Bianchi, and G. Carrozzo, "Towards the cross-domain interoperability of IoT platforms", in 2016 European Conference on Networks and Communications (EuCNC). 2016.

[4] Eisenmann, T., G. Parker, and M.W. van Alstyne, "Strategies for two-sided markets", Harvard Business review, 84(10), 2006, pp. 92-101.

[5] Gawer, A., "Bridging differing perspectives on tech-nological platforms: Toward an integrative framework", Research Policy, 43(7), 2014, pp. 1239-1249.

[6] Hagiu, A. and J. Wright, "Multi-sided platforms", International Journal of Industrial Organization, 43, 2015, pp. 162-174.
[7] Miorandi, D., S. Sicari, F. de Pellegrini, and I. Chlamtac, "Internet of things: Vision, applications and research challenges", Ad Hoc Networks, 10(7), 2012, pp. 1497-1516.

[8] https://iot-analytics.com/product/list-of-1600-enterprise-iot-projects-2018/, accessed 5-22-2018.

[9] https://www.apple.com/de/watch/compare/, accessed 5-30-2018.

[10] https:/de.statista.com/statistik/daten/studie/ 217342/umfrage/beliebteste-kategorien-im-app-storenach-anzahl-der-apps/, accessed 5-30-2018.

[11] http://www.dictionary.com/browse/domain, accessed 5-22-2018.

[12] Lee, I. and K. Lee, "The Internet of Things (IoT): Applications, investments, and challenges for enterprises", Business Horizons, 58(4), 2015, pp. 431-440.

[13] Gyrard, A., S.K. Datta, C. Bonnet, and K. Boudaoud, "Cross-Domain Internet of Things Application Development: M3 Framework and Evaluation", in 2015 3rd International Conference on Future Internet of Things and Cloud (FiCloud). 2015.

[14] Berners-Lee, T., J. HENDLER, and O.R.A. Lassil-ia, "The Semantic Web", Scientific American, 284(5), 2001, pp. 34-43.

[15] Bizer, C., T. Heath, and T. Berners-Lee, "Linked Data - The Story So Far", International Journal on Semantic Web and Information Systems, 5(3), 2009, pp. $1-22$.

[16] Di Noia, T., R. Mirizzi, V.C. Ostuni, D. Romito, and M. Zanker, "Linked open data to support contentbased recommender systems", ACM, 2012.

[17] Tiwana, A., Platform ecosystems: Aligning architecture, governance, and strategy, Morgan Kaufman, Waltham MA 2014.

[18] Gawer, A. and M.A. Cusumano, "Industry Platforms and Ecosystem Innovation", Journal of Product Innovation Management, 31(3), 2014, pp. 417-433.

[19] Schlagwein, D., D. Schoder, and K. Fischbach, "Social Information Systems: Review, Framework, and Research Agenda", ICIS 2011 Proceedings, 2011.

[20] Sagiroglu, S. and D. Sinanc, "Big data: A review", in International Conference on Collaboration Tech-nologies and Systems (CTS), 2013.

[21] Demchenko, Y., C. de Laat, and P. Membrey, "Defining architecture components of the Big Data Ecosystem", in International Conference on Collaboration Technologies and Systems (CTS), 2014.

[22] Atzori, L., A. Iera, and G. Morabito, "The Internet of Things: A survey", Computer Networks, 54(15), 2010, pp. 2787-2805. 
[23] Sheth, A., "Internet of Things to Smart IoT Through Semantic, Cognitive, and Perceptual Computing", IEEE Intelligent Systems, 31(2), 2016, pp. 108112.

[24] https://sixtwentyten.com/en, accessed 5-22-2018.

[25] https://codeforall.org/, accessed 5-22-2018.

[26] https://www.kaggle.com/, accessed 5-22-2018.

[27] Brocke, J., A. Simons, B. Niehaves, B. Niehaves, K. Reimer, R. Plattfaut, and A. Cleven, "Reconstructing the Giant: On the Importance of Rigour in Documenting the Literature Search Process", ECIS 2009 Proceedings, 2009.

[28] Benbasat, I., D.K. Goldstein, and M. Mead, "The Case Research Strategy in Studies of Information Systems", MIS Quarterly, 11(3), 1987, p. 369.

[29] Yin, R.K., Case study research: Design and methods, 5th edn., SAGE Publ, Los Angeles CA, 2014.

[30] Cooper, H.M., "Organizing knowledge syntheses: A taxonomy of literature reviews", Knowledge in Society, 1(1), 1988, pp. 104-126.

[31] Sundmaeker, H., P. Guillemin, P. Friess, and S. Woelfflé, Vision and challenges for realising the Internet of Things, Publications Office of the European Union, Luxembourg, 2010.

[32] Schreieck, M., M. Wiesche, and H. Krcmar, "Design and Governance of Platform Ecosystems - Key Concepts and Issues for Future Research", Research Papers, 2016.

[33] Delen, D. and H. Demirkan, "Data, information and analytics as services", Decision Support Systems, 55(1), 2013, pp. 359-363.

[34] https://www.cisco.com/c/dam/en_us/solutions/industries/docs/alaska-dot-ioe.pdf, accessed 5-23-2018.

[35] https://www.ibm.com/blogs/internet-of-things/ case-study-mahindra-mahindra/, accessed 5-23-2018.

[36] http://www.libelium.com/saving-water-withsmart-management-and-efficient-systems-in-spain/, accessed 5-23-2018.

[37] NACE Rev. 2: Statistische Systematik der Wirtschaftszweige in der Europäischen Gemeinschaft, Publications Office of the European Union, Luxembourg, 2008.

[38] Mell, P.M. and T. Grance, "The NIST Definition of Cloud Computing", Special Publication (NIST SP) 800-145, 2011.

[39] Verba, N., K.-M. Chao, A. James, D. Goldsmith, X. Fei, and S.-D. Stan, "Platform as a service gateway for the Fog of Things", Advanced Engineering Informatics, 33, 2017, pp. 243-257.

[40] http://www.libelium.com/the-city-of-tilburg-nl-becomes-smart-and-sustainable-teaming-with-libelium- and-ericsson-to-develop-an-iot-environmental-controlplatform/, accessed 5-23-2018.

[41] https:/www.smartparking.com/keep-up-todate/case-studies/transport-for-london-tfl-undergroundcar-parks, accessed 5-23-2018.

[42] Gutiérrez Bayo, J., International Case Studies of Smart Cities: Santander, Spain, Inter-American Development Bank, 2016.

[43] https://www.ptc.com/-/media/Files/PDFs/CaseStudies/J6684-Heidelberg-CS_EN_v1b.ashx, accessed 5-23-2018.

[44] Chaudhary, R., J.R. Pandey, P. Pandey, and P. Chaudhary, "'AGCO's Fuse Technology's' 'Connected Farm Services'", in Proceedings of the 2015 International Conference on Green Computing and Internet of Things (ICGCIoT). 2015.

[45] https://www.ptc.com/-/media/Files/PDFs/IoT/ J6081_CNH_Industrial_Case_Study_Final_11-1215.ashx, accessed 5-23-2018.

[46] https://customers.microsoft.com/enUS/story/rollsroycestory, accessed 5-23-2018.

[47] http://www.libelium.com/precision-farming-tocontrol-irrigation-and-improve-fertilization-strategieson-corn-crops/, accessed 5-23-2018.

[48] https://www.ptc.com/-/media/Files/PDFs/IoT /J6271_Carestream_CS_EN.ashx, accessed 5-23-2018. [49] McDougle T., Monsorez A., Maurel M., Lemoine C., "Smart Sensor network case study for drinking water quality monitoring", in Proceedings IWA Busan international congress, 17th - 21th September 2012.

[50] http://i.dell.com/sites/doccontent/corporate/casestudies/en/Documents/2016-elm-energy-10022678-iotoem-appliances-solutions.pdf, accessed 5-23-2018.

[51] https://www.intel.com/content/www/us/en/internet-of-things/case-studies/smart-support-healthcarecascade3d.html, accessed 5-23-2018.

[52] http://sofia2.com/home.html, accessed 6-1-2018. [53] http://www.ict-citypulse.eu, accessed 6-1-2018.

[54] http://fiesta-iot.eu, accessed 6-1-2018.

[55] Parker, G., M. van Alstyne, and X. Jiang, "Platform Ecosystems: How Developers Invert the Firm", MIS Quarterly, 41(1), 2017, pp. 255-266.

[56] https://www.iota.org/, accessed 5-31-2018.

[57] Haile, N., and J. Altmann, "Structural analysis of value creation in software service platforms", Electronic Markets, 26(2), 2016, pp. 129-142.

[58] Stahl, F., F. Schomm, and G. Vossen, "The data marketplace survey revisited", Working Papers, ERCIS(18), Münster, 2014. 


\begin{tabular}{|c|c|c|c|c|c|c|c|c|c|c|c|c|c|c|c|c|c|c|c|}
\hline \multirow{2}{*}{ 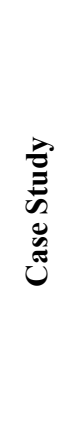 } & \multicolumn{4}{|c|}{ 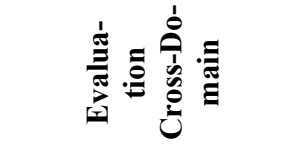 } & \multicolumn{4}{|c|}{ 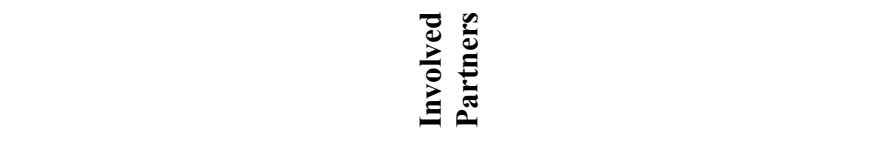 } & \multirow{2}{*}{ 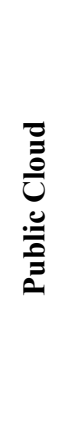 } & \multicolumn{2}{|c|}{ 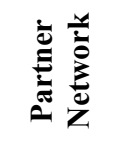 } & \multicolumn{3}{|c|}{ 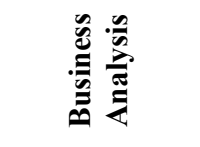 } & \multicolumn{3}{|c|}{$\stackrel{\stackrel{1}{\Xi}}{\stackrel{\Xi}{\Xi}}$} & \multirow{2}{*}{ 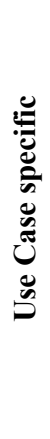 } & \multirow{2}{*}{ 这 } \\
\hline & 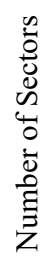 & 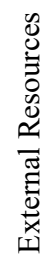 & 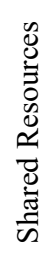 & 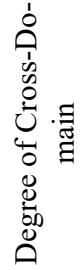 & $\begin{array}{l}\ddot{0} \\
\text { Dे } \\
\tilde{D}\end{array}$ & 离 & $\begin{array}{l}E \\
0 \\
\stackrel{ \pm}{0} \\
\frac{\pi}{2}\end{array}$ & 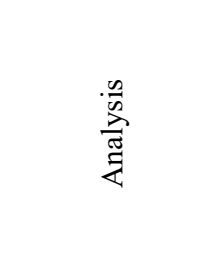 & & $\begin{array}{l}\frac{0}{\pi} \\
\frac{\pi}{\pi} \\
\frac{\pi}{\pi}\end{array}$ & $\begin{array}{l}\vec{d} \\
\mathscr{g}\end{array}$ & 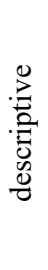 & 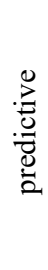 & 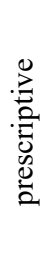 & 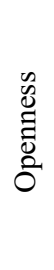 & $\begin{array}{l}\stackrel{\overbrace{}}{=} \\
: \frac{\pi}{0} \\
0 \\
0\end{array}$ & 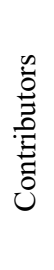 & & \\
\hline$[40]$ & 3 & 0 & $\bullet$ & high & Libelium & Libelium & $\begin{array}{c}\text { Ericsson IoT } \\
\text { Accelerator }\end{array}$ & $\begin{array}{c}\text { Ericsson IoT } \\
\text { Accelerator }\end{array}$ & $\bullet$ & $\bullet$ & $\bullet$ & $\bullet$ & $\bullet$ & 0 & $\bullet$ & 0 & 0 & 0 & $\begin{array}{c}\text { City Council, } \\
\text { Citizens }\end{array}$ \\
\hline [41] & 2 & 0 & $\bullet$ & high & $\begin{array}{l}\text { Smart Park- } \\
\text { ing }\end{array}$ & Smart Parking & Smart Parking & Smart Parking & $\bullet$ & ० & 0 & $\bullet$ & $\circ$ & ० & 0 & 0 & $\circ$ & $\bullet$ & $\begin{array}{l}\text { Public Admin- } \\
\text { istration, Pas- } \\
\text { sengers }\end{array}$ \\
\hline [42] & 6 & 0 & $\bullet$ & high & Libelium & Libelium & $\begin{array}{c}\text { FIWARE, Te- } \\
\text { lefonica IDAS, } \\
\text { SmartSantander } \\
\text { Portal Server }\end{array}$ & $\begin{array}{l}\text { SmartSantander } \\
\text { Portal Server }\end{array}$ & o & $\bullet$ & $\bullet$ & $\bullet$ & $\bullet$ & ० & $\bullet$ & $\bullet$ & $\bullet$ & 0 & $\begin{array}{l}\text { City Council, } \\
\text { Citizens, Local } \\
\text { Companies }\end{array}$ \\
\hline [43] & 1 & 0 & $\bullet$ & low & Heidelberg & (Heidelberg) & ThingWorx & (Heidelberg) & ० & $\bullet$ & o & $\bullet$ & $\bullet$ & ० & 0 & 0 & 0 & $\bullet$ & $\begin{array}{l}\text { Customers, } \\
\text { Heidelberg }\end{array}$ \\
\hline$[44]$ & 1 & $\bullet$ & o & low & AGCO & AGCO & AGCO & AGCO & o & o & 0 & $\bullet$ & o & o & ० & 0 & o & $\bullet$ & Farmers \\
\hline [45] & 1 & 0 & $\bullet$ & low & $\begin{array}{c}\text { (CNH Indus- } \\
\text { trial) }\end{array}$ & $\begin{array}{c}\text { (CNH Indus- } \\
\text { trial) }\end{array}$ & ThingWorx & $\begin{array}{c}\text { (CNH Indus- } \\
\text { trial) }\end{array}$ & 0 & $\bullet$ & $\bullet$ & $\bullet$ & $\bullet$ & 0 & $\bullet$ & $\bullet$ & 0 & $\bullet$ & $\begin{array}{c}\text { Customers, } \\
\text { Suppliers }\end{array}$ \\
\hline [46] & 1 & $\bullet$ & 0 & low & $\begin{array}{l}\text { (Rolls } \\
\text { Royce) }\end{array}$ & n.a. & $\begin{array}{l}\text { Microsoft Az- } \\
\text { ure }\end{array}$ & $\begin{array}{c}\text { Microsoft Cor- } \\
\text { tana Intellig. } \\
\text { Suite } \\
\end{array}$ & $\bullet$ & $\bullet$ & 0 & • & $\bullet$ & ० & o & 0 & $\circ$ & ० & Rolls Royce \\
\hline [47] & 1 & $\bullet$ & o & low & Libelium & - & Omicafarm & Omicafarm & o & $\bullet$ & $\bullet$ & $\bullet$ & $\bullet$ & ० & o & 0 & o & $\bullet$ & Customers \\
\hline$[48]$ & 1 & 0 & $\bullet$ & low & (Carestream) & (Carestream) & ThingWorx & (Carestream) & o & $\bullet$ & ० & $\bullet$ & $\circ$ & ० & 0 & 0 & $\circ$ & $\bullet$ & $\begin{array}{c}\text { Customers, } \\
\text { Suppliers }\end{array}$ \\
\hline [49] & 1 & 0 & 0 & not & Endetec & n.a. & n.a. & Veolia & o & o & 0 & $\bullet$ & 0 & o & 0 & 0 & 0 & $\bullet$ & Veolia \\
\hline$[50]$ & 1 & 0 & 0 & not & $(\mathrm{ELM})$ & $\begin{array}{l}\text { Dell Edge } \\
\text { Gateway }\end{array}$ & n.a. & n.a. & 0 & $\bullet$ & 0 & $\bullet$ & 0 & o & 0 & 0 & $\circ$ & o & ELM \\
\hline [36] & 1 & 0 & 0 & not & Libelium & Libelium & Sofia2 & $\begin{array}{l}\text { A-Cing, Nov- } \\
\text { elti }\end{array}$ & $\bullet$ & $\bullet$ & $\bullet$ & $\bullet$ & o & ० & 0 & 0 & $\circ$ & $\bullet$ & $\begin{array}{l}\text { Public Admin- } \\
\text { istration }\end{array}$ \\
\hline [51] & 1 & 0 & 0 & not & Fibaro & Wind River & $\begin{array}{c}\text { Cascade3D An- } \\
\text { alytics }\end{array}$ & $\begin{array}{l}\text { Cascade3D An- } \\
\text { alytics }\end{array}$ & 0 & $\bullet$ & $\bullet$ & - & 0 & 0 & 0 & 0 & 0 & 0 & Headfirst \\
\hline
\end{tabular}

Table 6: Classification and evaluation of case studies (• - yes, o - no, n.a. - not described, () - no explicit declaration (e.g. white label), - - not used) 